\title{
MONTESQUIEU, LEDOR DE HOBBES ${ }^{1}$
}

\author{
Alfredo Attié $J r^{2}$ \\ Doutor em Filosofia pela Faculdade de Filosofia, Letras e \\ Ciências Humanas da USP; Mestre em Filosofia e Teoria \\ Geral do Direito pela Faculdade de Direito da USP
}

“... que chamamos de criação, mistura de esquecimento e lembrança do que lemos"

\begin{abstract}
Resumo:
Em duas cenas, o autor disserta sobre Montesquieu, desde 1711 até a publicação, vinte anos depois, em 1748, de uma obra na qual contesta o sis-tema de Hobbes, enfatizando não ser razoável o vislumbre dos homens ao se prejudicarem. Na tomada final, Montesquieu se demonstra anti-Hobbes.
\end{abstract}

\begin{abstract}
:
In two scenes, the author dissertate on Montesquieu, since 1711 until the publication, twenty years later, in 1748 , of a workmanship in which contests the system of Hobbes, emphasizing not to be reasonable the glimpse of the men when they harm themselves. In the final taking, Montesquieu demonstrates itself an anti-Hobbes.
\end{abstract}

Unitermos: Montesquieu; Hobbes; Justiça natural; estado de natureza.

1. Primeira cena: Montesquieu inicia, em 1711, enquanto divertimento, nos momentos em que descansa do estudo dos códigos, a jornada epistolar de seus

1. Respeitosamente dedicado aos Professores Doutores Renato Janine Ribeiro, Fábio Konder Comparato e Miguel Angel Ciuro Caldani.

2. Realizou pesquisa na Universidade de Coimbra, Faculdade de Direito, como bolsista do Governo da República portuguesa. Juiz de Direito. Foi Procurador e Advogado do Estado de São Paulo. Foi Docente Voluntário do Departamento de Filosofia e Teoria Geral do Direito da FDUSP. Autor de Pó da Obliqüidade: desigualdade e diferenģa - Ensaios de Outro Direito, 2000, e Tópica das paixões e Estilo Moraliste, 2000. 
persas, que fará publicar dez anos depois. Engendra a idéia de uma Justiça natural, ao narrar a história dos trogloditas, assim condenando, desde que faz desencadear sua reflexão política, a elaboração hobbesiana do estado de natureza.

Segunda cena: Montesquieu, na obra que coroa sua tarefa intelectual, tendo-lhe custado vinte anos de trabalho, publicada em 1748, reserva um lugar privilegiado, na abertura do texto, à contestação do sistema de Hobbes, afirmando que o desejo que teria vislumbrado nos homens, de se subjugarem uns aos outros, não seria razoável.

Entre essas tomadas, nas quais o filósofo torna públicas suas cautelas em relação a Hobbes, projetam-se outros tantos momentos de crítica, guardados da leitura geral nos Pensamentos e no Espicilégio.

Tomada final: Montesquieu se apresenta como o anti-Hobbes, pioneiro na advertência da Ilustração, quanto a seus desatinos; define-se como seu adversário.

Desse modo, a história da filosofia logrou sedimentar a imagem de um abismo, intransponível obstáculo entrc os pensamentos de Montesquieu e Hobbes.

Enfim, não seria o aristotélico magistrado de La Brède infenso ao estado de natureza hobbesiano? O iluminismo não se mostraria inimigo enfurecido da doutrina absurda do autor do De corpore politico? O século XVIII, ainda, não teria determinado a derrocada de suas concepções políticas, cabendo a Montesquieu a primazia nesse prematuro acerto de contas?

2. Se se deseja, todavia, trabalhar no espaço de uma história da filosofia, e não da mera comparação entre doutrinas de autores distintos, tal concepção esquemática não deve prevalecer. No mínimo porque somente pode levar à óbvia conclusão de que, de fato, os autores permanecem distintos. Ou, talvez, endosse a idéia de uma história que não-passa de um jogo muito peculiar, no qual os sucessores impõem as regras a seus adversários, que teriam, sem mesmo presumirem sua participação no embate, lançado mão de todos os seus trunfos.

Não se duvida de que esse tabuleiro da diacronia tenha sido oferecido pelos setecentistas a seus antepassados. Basta observar a acentuação do espírito de distinção do século XVIII - em D'Alembert, por exemplo ou a vertente oposta, representada por La Harpe, na qual o conjunto da produção filosófica desta era seria muito inferior às proezas daquela de Luís XIV. Enquanto os editores do Dictionnaire raisonné consideravam o goût dominant de sua época o ponto culminante dos progrès 
de l'esprit, que, partindo da erudição, passando pelas Belas-Letras, teriam alcançado a Filosofia, o autor do Lycée acusava o mero caráter pretensioso desse auto-elogio: " $a$ característica geral, muito marcada no século dezoito, principalmente nos últimos cinqüenta anos, tem sido o mais vergonhoso abuso do espírito e do raciocínio em todos os gêneros, sucedendo-se aos mais belos esforços da Razão e do gênio" empreendidos durante o classicismo francês, tão superior "em todas as artes de imitação, em tudo aquilo que estabelece e embeleza a ordem social"

Nesta polêmica, interessa o fato de os contendores tocarem-se, ao fixarem a necessidade de distinguir uma era da outra, pouco importando se a escala em que as inșerem ascenda ou decaia, consoante o gosto do crítico. Ou, mais especificamente, sua capacidade de apreender a grandeza ou a inferioridade do século da filosofia: "não nos espantemos, pois, se nossas Obras de espírito são em geral inferiores às do século precedente. Podemos mesmo encontrar sua razão nos esforços que fazemos para superar nossos predecessores"... O século "quer acrescentar ao que recebeu e erra o alvo ao procurar ultrapassá-lo. Têm-se, portanto, ao mesmo tempo, maior número de princípios para julgar corretamente, um acervo maior de luzes, um maior número de bons juizes e um menor número de boas Obras"... Decréscimo na quantidade, muito embora sobressaiam os homens de mérito, que deixam à posteridade "monumentos de que tem todo direito de glorificar-se" Daqui os exemplos se seguem, entre eles o do "Escritor sensato, tão bom cidadão quanto grande Filósofo" que lhes deu "sobre os princípios das Leis uma obra depreciada por alguns franceses e estimada por toda a Europa" (D'Alembert).

E, se tomarmos o caso específico de Hobbes, os dardos lançados pelo setecentos foram implacáveis: "horrivel sistema de Hobbes e descobriremos, bem ao contrário de sua doutrina absurda, que, muito longe de o estado de guerra ser natural ao homem, a guerra nasceu da paz, ou ao menos das precauções que os homens tomaram para assegurar uma paz durável" (Rousseau); "Todo aquele que estuda a moral deve começar refutando teul livro em seu coração; mas teu próprio coração te refutaria ainda mais, pois tu foste tão virtuoso... e só te faltou... ensinar os verdadeiros princípios da virtude que praticavas e que recomendavas aos outros"(Voltaire).

Podemos admitir a existência de motivos para a busca da diferença e a recusa dos textos hobbesianos, no interior da polêmica, e mesmo buscar compreendêlos no seio da história que pulsava no interior dos discursos. Surpreende, entretanto, que os críticos posteriores não apenas tenham adotado as regras, mas continuado a partida do ponto em que lhes foi deixada. 
Alguma estranheza, enfim, seria causada se se negasse a idéia de o écrivain judicieux, bon citoyen, grand Philosophe mostrar-se o antípoda de l'affreux M. Hobbes, profond et bizarre philosophe.

3. Propõe-se, aqui, retomar a leitura que Montesquieu fez de Hobbes.

Em outros termos, refazer, neste ponto específico, uma perspectiva da história da filosofia que trabalhe com a recepção dos textos. Recuperar o fio mais sutil que, longe da simples comparação das idéias, faz migrá-las e constrói o tecido histórico.

A leitura é, com efeito, o lugar em que reside a história do pensamento. Não porque lhe estipule limites, mas exatamente por dissipá-los.

A experiência do autor que escreve supre um vazio na comunicação entre ele e o autor que lê - mas cria outros tantos espaços abertos para a imaginação desperta-o para uma situação diversa, deixa-lhe perguntas novas que, em sua maior parte, não tinham sido cogitadas pelo escritor e muito menos podem ser respondidas por ele -, induz o leitor a um outro processo de criação.

Não há um prazer na leitura senão quando encaminha a imaginação a uma nova tarefa de escrever.

É o que, por exemplo, está claramente na crítica que Proust fez a John Ruskin, em 1905: "sentimos muito bem que nossa sabedoria começa onde a do autor termina, e gostaríamos que ele nos desse respostas, quando tudo o que ele pode fazer é dar-nos desejos. Estes desejos, ele não pode despertar em nós senão fazendo-nos contemplar a beleza suprema à qual o último esforço de sua arte lhe permitiu chegar ... O que é o fim de sua sabedoria não nos aparece senão como começo da nossa ... Este é o preço da leitura e esta a sua insuficiência"

Enfim, os livros teriam sido escritos para a leitura de outros tantos escritores. Poderíamos pressupor, portanto, que, ao ler Hobbes, Montesquieu o faz reviver em sua pena, naquilo que a teoria da estética da recepção chamaria de uma série literária (Jauss).

O que a crítica estabelece como oposição radical, pode não passar, na perspectiva de uma observação menos literal, da superação do horizonte de expectativa do autor-escritor, em que o autor-leitor parte para a solução de outras indagações sugeridas pela experiência de sua leitura, sempre mais ampla do que a pura sequiência de palavras no texto lido.

Há, neste passo, a intervenção do que o autor-leitor parece não ter dito, 
ao fazer pública sua impressão do que leu. Quer dizer, as poucas objeções expressas que Montesquieu faz a Hobbes não trariam em si uma assimilação, esta sim mais ampla ou relevante, da experiência hobbesiana?

Numa observação menos esquemática, menos marcada pelos preconceitos de uma história da filosofia de etapas previamente fixadas, podem aparecer inúmeros pontos de convergência, que modulem a visão generalizada da fïgura do confronto absoluto, que se realiza na fórmula: - Montesquieu tinha que criticar Hobbes, uma vez que a cosmovisão das Luzes contraria a cosmovisão do século da geometria, o que facilita a operação de pinçar os termos da contestação - a originalidade e o gênio dos autores comparados os oferecem em abundância.

O tempo cronológico não passa de mero coadjuvante na trama, no desenrolar da história cultural: "a multiplicidade de acontecimentos que ocorrem num determinado momento histórico, e que se pretende compreender, na perspectiva de uma história universal, como expressões representativas de um só é único sentido, pertencem de fato a curvas de tempo absolutanente diferentes, submetidas às leis específicas de sua história particular ... A coerência da 'história geral' nasceria sempre do olhar retrospectivo e do discurso dos historiadores, autores de uma unidade artificial" O problema se agrava quando a coerência construída acaba por obliterar as mudanças de pensamento do próprio autor, vendo-se sempre a obra anterior como preparação das seguintes, consideradas mais acabadas, perfeitas.

Interessa o modo como o autor-leitor compreende, do ponto de vista diacrônico, o texto do autor-escritor. Não necessariamente Montesquieu leu Hobbes como um homem de um século passado.

4. O magistrado de Bordeaux tomou Hobbes como um contemporâneo. Com efeito, é o que se observa, por exemplo, logo na primeira vez em que o refere, em seus Pensamentos: "é um princípio falso aquele de Hobbes: que, o povo tendo autorizado o príncipe, as ações do príncipe são as ações do povo, e, por conseqüência, o povo não pode se queixar do príncipe, nem exigir contas de suas ações: porque o povo não pode se queixar do povo. Assim Hobbes esqueccu seu princípio do Direito Natural: Pacta esse servanda. O povo autorizou o piíncipe sob condição; ele a estabeleceu sob a forma de uma convenção. Énecessário que ele a observe, e o príncipe não representa o povo senão como o povo quis ou se presume ter desejado que ele o representasse. Além disso, é falso que aquele que é delegado tenha tanto poder quanto aquele que delega, e que não dependa mais dele" 
A objeção que estabelece é lógica, o termo que a define é "faux". Hobbes não teria tirado conclusões corretas de seus princípios.

É interessante notar que Montesquieu assume a hipótese hobbesiana do estado de natureza, ao considerar que o povo alutorizou o príncipe sob condição, estabelecida sob a forma de uma convenção, ou, mais propriamente: "avant toutes ces lois, sont celles de la nature, ainsi nommées, parce qu'elles dérivent uniquement de la constitution de notre être. Pour les connoître bien, il faut considérer un homme avant l'établissement des sociétés. Les lois de la nature seront celles qu'il recevroit dans IIn état pareil". Montesquiieu toma mesmo o termo no duplo sentido hobbesiano: condição natural dos homens e seu estado fora da sociedade civil. Quer dizer, os homens segundo a condição de seu nascimento e suprimido o estado social ou considerado um momento anterior a essa associação.

Neste passo, seria interessante observar que nossos autores escritor e leitor - empregam procedimentos que os aproximam: o gosto por argumentar com o uso da ficção, tão típico dos jurisprudentes, e o prazer de construir jogos, constitutivo de toda produção cultural (Huizinga), como o Direito, área em que Hobbes e Montesquieu se gabavam, com razão, de seus conhecimentos.

No que diz respeito ao primeiro, Hobbes abre o Leviathan com o termo natureza. Parece, ao fazê-lo, querer adotar uma ironia, uma vez que seu objetivo é o artifício (imitatio naturae), característica, evidentemente, da poiesis, ainda apoiada na praxis, como na antigüidade: "a Natureza a Arte pela qual Deus fez e governa o Mundo - é, como em muitas outras coisas, também nisto imitada pela Arte do homem, a ponto de poder fazer um Animal Artificial ... a Arte vai mais longe, initando o Homem, mais excelente e Racional artefato da Natureza. Pois pela Arte criou-se esse grande Leviathan ... não outra coisa senão um Homem Artificial; ainda que maior em estatura e força do que o Natural..."

A reunião dos homens é resultado de um artificio, de um acidente, não decorre de nenhuma razão natural: "não procuramos companhia naturalmente e só por si mesma, mas para dela recebermos alguma honra ou proveito; estes nós desejamos primariamente, aquela só secundariamente ... Toda rennião, por mais livre que seja, deriva quer da miséria recíproca, quer da vã glória, de modo que as partes rennidas se empenham en conseguir algum benefício ... Toda associação, portanto, ou é parao ganho ou para a glória isto é: não tanto para o anor de nossos próximos, quanto pelo amor de nós mesmos" Hobbes não descarta a paixão chamada amor (de si e de outrem o par egoísmo-altruísmo), tão-somente faz prevalecer o medo, que impõe 
limites à possibilidade da dominação: "embora os beneficios desta vida possam ser ampliados, e muito, graças à colaboração recíproca, contudo - comio podem ser obtidos com mais facilidade pelo domínio, do que pela associação com outrem -, espero que ninguém vá duvidar de que, se fosse removido todo o medo, a natureza humana tenderia com toda avidez à dominação do que a construir uma sociedade"

Longe de significar pavor, o medo corresponde a "uma antevisão de um mal futuro; por isso não penso que fugir seja o línico efeito do medo; a quem sente medo também ocorre desconfiar, suspeitar, acautelar-se e até mesmo agir de modo a não mais temer ... É pelo medo que os homens se protegen, até mesmo pela fuga, e escondendo-se pelos cantos, se não têm outro jeito de escapar; mas, o mais das vezes, utilizando-se de armamentos e armas defensivos. Assim acontece que, se eles têm a coragem de se mostrar, cada um vem a conhecer en que disposição está o outro; de modo que assim, se lutarem, a sociedade civil nasce da vitória, e, se concordam, vem de seu acordo"

Montesquieu redargüe: "l'idée de l'empire et de la domination est si composée, et dépend de tant d'autres idées, que ce ne seroit pas celle qu'il auroit d'abord ... On ne sent pas que l'on attribue aux hommes, avant l'établissement des sociétés, ce qui ne peut leur arriver qu'après cet établissement, qui leur fait trouver des motifs pour s'attaquer et pour se défendre. Au sentiment de sa faiblesse, l'homme joindroit le sentiment de ses besoins. Ainsi une autre loi naturelle seroit celle qui lui inspireroit de chercher à se nourrir. J'ai dit que la crainte porteroit les hommes à se fuir: mais les marques d'une crainte réciproque les engageroit bientôt à s'approcher"

Montesquieu concede ao medo um lugar de preeminência. Trata-se de uma paixão natural que, ao mesmo tempo, leva à separação e ao engajamento humano. E indagaríamos se esta concepção não poderia ser assimilada pelo sistema hobbesiano, especificamente no que se refere ao instante em que os homens resolvem, atendendo ao reclamo de paixões e à indicação da razão, constituir a associação: "the Passions that encline men to Peace, are Feare of Death; Desire of such things as are necessary to commodious living; and a Hope by their Industry to obtain them. And Reason suggesteth convenient Articles of Peace, upon which men may be drawn to agreement" Resta acrescentar que para Montesquieu, a par do medo, outras paixões encaminham à vida social, como o "plaisir qu'un animal sent à l'approche d'un animal de son espèce" o "charme que les deux sexes s'inspirent par leur différence" "la prière naturelle qu'ils se font toujours l'un à l'autre" e o "désir de vivre en société" assim como a faculdade humana do conhecimento, formando outras tantas prescrições naturais. 
É claro, existem outros instantes em que o barão de La Brède recusa até a validade de se indagar sobre o estado de natureza, teclas que a crítica não cansa de apoiar, fazendo olvidar as falhas que comprometem a pretensa coerência da imagem do antípoda.

A própria cena do estado de natureza traz o sabor ficcional à obra. Hobbes solicita ao leitor um esforço de imaginação, que abstraia sua condição social, tornandose atento a certas atitudes inconscientes que, segundo ele, remeteriam - como no labor psicanalítico - à essência mesma de sua condição (nosce teipsum, read thy' self): "objetareis, possivelmente, que há alguns que negam isso... Na verdade não me contradigo, mas eles sim, cujas ações desnentem o que seus discursos aprovam ... não dormem sem fechareì - não-só suas portas, para proteção de seus concidadãos - mas até seus cofres e baús, por temor aos domésticos"; "it may be thought, there was never such a time, nor condition of warre as this; and I believe it was never generally so, over all the world ... Howsoever, it may be perceived what manner of life there would be, where there were no common Power to feare; by the manner of life, which men that have formerly lived under a peacefull government, use to degenerate into, in a civill Warre. But though there had never been any time, wherein particular men were in a condition of warre one against another; yet in all times, Kings, and Persons of Soveraigne authority, because of their Independency, are in continuall jealousies, and in the state and posture of Gladiators..."

Neste contexto, dada a afirmação de Hobbes de que, conseqüentemente, numa guerra de todos contra todos, "nothing can be Unjust", deseja-se cerrar qualquer possibilidade de diálogo com o pensamento de Montesquieu, para o qual a "Justice n'est pas dépendante des lois humaines, qu'elle est fondé sur l'existance et la sociabilité des êtres raisonnables, et non pas sur des dispositions ou volontés particulières de ces êtres"

Nossos autores, todavia, estão falando de coisas muito diferentes. Hobbes não-nega que possam existir homens justos, mas concede à Justiça uma caráter social estrito: "where there is no common Power, there is no Law, no Injustice" porque, na guerra, a força e a fraude seriam as virtudes cardeais. Justiça e injustiça são "Qualities, that relate to men in Society, not in Solitude" assim como Propriety e Dominion. Montesquieu não-nega a presença de uma Justiça natural porque, para ele, a Justiça é uma paixão, como toda virtude é um sentimento e não uma seqüência de conhecimentos, algo, reconhecidamente, très pénible, porque uma paixão de contenção.

Na história dos trogloditas, que Usbek conta a Mirza, em que Montesquieu exercita seu talento ficcional, viu-se, também, contestação a Hobbes. Contudo, o texto indica mais a influência hobbesiana do que contradição. 
O viajante persa deseja estabelecer uma verdade moral, menos persuadindo do que fazendo seu interlocutor sentir a lição que do conto se extrai.

A pergunta proposta por Mirza e que a história vai responder é olvidada pelos intérpretes: "se são os prazeres e a satisfação dos sentidos que tornam os homens felizes, ou a prática da virtude" Tanto os prazeres quanto as virtudes são paixões, portanto falam aos sentidos. Contudo, remetendo aos Interiour Begginings of Voluntary Motions, relacionam-se como os apetites ou desejos e as aversões, que formam os pares de paixões. Os prazeres, para empregar os termos de Hobbes, denotam um esforço em direção a alguma coisa que é sua causa. As virtudes contêm o desejo, esforçam-se para evitar alguma coisa. Montesquieu também não desconhecia a distinção romana entre ius e lex, que Hobbes recupera, associando-a ao quadro das paixões.

Assim como Hobbes, Montesquieu vê o homem como um ser de paixões, deixando à razão um papel menos importante. A razão primitiva de que fala o capítulo inicial do Espírito das leis não passa do produto de uma regularidade no curso das paixões. A vida humana transita em meio a tais apetites e aversões, constituindo-se no cenário de seu progresso. Nas Cartas Persas, as paixões encontram-se em um movimento quase caótico. No Espírito das Leis encontrarão seu repouso quando assentadas nos regimes políticos.

A Montesquieu também foi difícil encontrar um povo em situação de inexistência de coerção social. Os trogloditas, destarte, possuíam governo, mas se rebelaram tanto contra o governante imposto quanto contra aquele que escolheram, "concordaram em não obedecer mais a ninguém, cada um zelaria unicamente por seus interesses, sem consultar os dos outros". Destruíram-se, "vítimas de sua própria maldade e injustiça". Permaneceram, porém dois homens "bem singulares: conheciam a justiça, eram humanos, amavam a virtude". A compaixão motivou-lhes o acerto de uma nova aliança. Recuperaram a civilização dos trogloditas, criaram instituições e festividades; até que escolhessem um novo governante, viveram apenas sob o jugo da virtude.

De resto, a história dos ciclos de grandeza e decadência dos trogloditas não corresponde à hipótese do estado de natureza de Hobbes, e igualmente se distingue daquela de Locke. O que, em resumo, coloca Montesquieu diante de indagações diversas, não abandonando, contudo sua condição de leitor privilegiado.

5. Nas Cartas Persas, a ficção e o jogo constituem a própria fïlosofia.

Tem-se procurado extrair as lições de Montesquieu a partir da citação de uma ou outra passagem do texto. O procedimento é, necessariamente, equivocado, 
uma vez que suprime o encadeamento da narração e o prazer do romance, do jogo que aos poucos vai se desenrolando: "o que mais agradou nas Cartas Persas foi que os leitores puderam encontrar nelas sem que o esperassem - uma espécie de romance. Tem começo, andamento e fim. Os vários personagens são encadeados numa história que os liga ... Essa espécie de romance costuma alcançar sucesso, porque nela cada um expõe em pessoa sua situação atual - o que nos leva a sentir as paixões melhor do que qualquer narrativa poderia fazer ... Na forma de cartas...os atores não são selecionados...os assuntos tratados não dependem de nenhum propósito ou plano previamente elaborado, o escritor goza da vantagem de poder acrescentar a filosofia, a política e a moral a.um romance, e de articular o conjunto inteiro por meio de uma cadeia secreta e, por assim dizer, desconhecida ... Todo o agrado desta obra só podia consistir no eterno contraste entre as coisas reais e a maneira singular, nova ou estranha, pelas quais elas eram percebidas"

Como o compromisso do autor com as idéias que seus personagens expõem nas epístolas é muito tênue - isto quando não deixa a questão em aberto, compele o leitor a participar, cobrindo claros os críticos buscaram confirmar as opções do escritor em suas obras posteriores, chegando mesmo a afirmar que as Cartas Persas e o Espírito das Leis seriam um só livro, ou que a primeira constituiria o esboço e a segunda o acabamento. Em nome da coerência, destrói-se a especificidade de um pensamento.

O divertimento do romance resiste, como jogo, a "toda análise e interpretação lógicas" que suspenderiam seu "caráter profundamente estético"

A filosofia, a moral, a política ali se encontram, mas a cadeia que as une ao enredo permanece secreta, quer dizer, somente o leitor pode optar no lugar do escritor, na medida em que endosse a opinião de certo personagem. Observe-se que cada um possui o seu interlocutor privado. Quem torna manifesta a trama é o selecionador das missivas. O leitor necessita adivinhar o jogo da escrita $\mathrm{c}$ da recepção, a partir de suas próprias paixões e não de sua razão: "o jogo, seja qual for a sua essência, não é material ... ultrapassá os limites da realidade física"

6. Finalmente, em Hobbes, o caráter lúdico aparece na concepção do contrato, forma elementar da geometria política, espalhando-se por toda a construção planejada do Leviathan, livro e artefato.

A questão do jogo no Direito é abordada por Huizinga exclusivamente em sua faceta de processo. Todavia, a idéia do contrato aparece quando refaz a concepção original do termo wedding (casamento), que remontaria "aos primeiros 
alvores da história jurídica e social. Wedding relaciona-se com a wedde, penhor simbólico mediante o qual alguém se compromete a obedecer a uma convenção"

Em Hobbes, o contrato encerra o universo da guerra e impõe o império da palavra, contudo isenta dos abısos que podem perpetuar a situação de conflito. Substitui o desenrolar ilimitado dos desejos por regras bem estabelecidas a partir do atributo da soberania. Suprime a luta e impõe a perspectiva do soberano para a culturct da corte: "a cultura de corte tem uma tendência especial para adotar a forma do jogo, dado o fato de mover-se dentro de un círculo restrito. O respeito que se sentia na presença do imperador era por si só suficiente para impor toda espécie de regras e fiç̧ões"

E a doutrina do contrato é bastante específica, ao estabelecer suas regras e ficções.

Essa idéia de montagem da sociedade a partir de um princípio que conduz todo o seu movimento ou constância: " $a$ Common-wealth is said to be Instituted, when a Multitude of men do Agree, and Covenant, every one, with every one, that to whatsoever Man, or Assembly of Men, shall be given by the major part, the Right to Present the Person of them all, (that is to say, to be their Representative;)every one, as well he that Voted for it, as he that Voted against it, shall Authorise all the Actions and Judgements, of that Man, or Assembly of men, in the same manner; as if they were his own, to the end, to live peceably amongst themselves, and he protected against other men. From this Institution of a Common-wealth are derived all the Rights, and Facultyes of him, or them, on whom the Soveraigne Power is conferred by the consent of the People assembled" não passa de um jogo imposto por uma convenção, isto é, uma fiç̧ão que todos aceitam como maneira de sustar a guerra.

Montesquieu conserva esse procedimento, muito embora tenha se mostrado mais complexo na confecção de seu tabuleiro. Cada forma de governo tem seu princípio, que conforma a sociedade e mantém disciplinadas as paixões, pela prevalência de uma, que nomeia a natureza do regime.

São Paulo, janeiro de 2001 .

3. Para outras questões pertinentes na leitura de Hobbes por Montesquieu e para bibliografia, consultese a tese de doutorado: ATTIÉ Jr., A. Momtesquieu: tópica das paixões e estilo moraliste. FFLCH.USP., 2000. 